\title{
Sistem Informasi Pengelolaan Data Kemahasiswaan Berbasis Website pada STIA Satya Negara Palembang
}

\author{
Web-Based Student Data Management Information System at \\ STIA Satya Negara Palembang
}

\author{
Dyah Handayani ${ }^{1}$, Fitria Choirunisa ${ }^{2}$, Dicky Pratama ${ }^{3}$ \\ ${ }_{1,2,3}$ Program Studi Sistem Informasi, STMIK GI MDP \\ E-mail: ${ }^{1}$ dyahhandayani09@mhs.mdp.ac.id, ${ }^{2}$ fitria.choirunisa11@mhs.mdp.ac.id, \\ 3dqpratama@mdp.ac.id
}

\begin{abstract}
Abstrak
Pendidikan merupakan proses untuk menyiapkan peserta didikmelalui masa bimbingan proses belajar mengajar sebagai bentukpelatihandalam mengembangkan kepribadian, serta kemampuan seorang peserta didik yang nantinya kemampuan tersebut dapat dimanfaatkan di dunia kerja setelah menjadi alumni. Suatu perguruan tinggi sangat membutuhkan informasi mengenai data alumninya, jurusannya, tahun kelulusannya, tempat para alumni tersebut bekerja.Tak terkecuali dengan STIA Satya Negara yang masih belum memiliki suatu sistem informasi yang mampu menyimpan mengelola data-data alumni, hal ini sangat menyulitkan pihak kampus seperti lambatnya bidang kemahasiswaan dalam merekap laporan data alumni, carrier center, prestasi mahasiswa, kegiatan UKM oleh karena itu akan dirancang dan dibangun dengan sistem informasi pengelolaan data kemahasiswaan berbasis website pada STIA Satya Negara untuk menyimpan data-data alumni secara terstruktur. Proses pembangunan sistem informasi pengelolaan data alumni ini menggunakan metodologi Iterasi yang dimulai dari fase perencanaan, analisis, perancangan, implementasi, hingga pemeliharaan. Menggunakan bahasa pemprograman PHP dengan menggunakan basis data MySQL dan XAMPP. Website ini diharapkan dapat mengatasi masalah seperti memudahkan bidang kemahasiswaan dalam melakukan rekap laporan data alumni, mempercepat membagi informasi lowongan pekerjaan tanpa harus datang ke kampus, memudahkan pihak kampus maupun perusahaan untuk mencari mahasiswa yang berprestasi, dan memudahkan pihak kampus meng-update UKM yang ada sehingga mahasiswa ikut berpartisipasi tehadap kegiatan-kegiatan yang ada.
\end{abstract}

Kata kunci : Metodologi Iterasi, PHP, MySQL, dan XAMPP

\begin{abstract}
A university really needs information about its alumni data, majors, graduation year, where the graduate work. No exception to STIA Satya Negara which still does not have an information system capable of storing managing alumni data, this is very difficult for campuses such as the campus the slow pace of student affairs in recapitulating alumni data reports, carrier centers, student achievements, UKM activities will therefore be designed and built with a website-based student data management information system on STIA Satya Negara to store graduate structured data. The process of building an graduate data management information system uses the Iteration methodology, which starts from the planning, analysis, design, implementation, and maintenance phases. This website is expected to be able to overcome problems such as facilitating student affairs in recapitulating alumni data reports, accelerating sharing job vacancies information without having to come to campus, making it easier for campuses and companies to find outstanding students, and making it easier for the campus to update existing SMEs so that students participate in the existing activities
\end{abstract}

Keywords: Iteration Methodology, XAMPP, MySQL 


\section{PENDAHULUAN}

Dalam dunia sekolah, pendidikan sangat penting untuk pelatihan dan mengembangkan kepribadian serta keahlian peserta didik yang nantinya keahlian tersebut dapat dimanfaatkan di dunia kerja setelah menjadi alumni. Pihak perguruan tinggi pun tentunya membutuhkan Teknologi Informasi (TI) untuk mendukung tridarma seperti pendidikan, penelitian dan pengabdian kepada masyarakat (PKM). Pemanfaatan TI diharapkan menghasilkan manfaat seperti keefektifan proses belajar mengajar, keefesienan pengelolaan administrasi akademik, dan pengelolaan informasi akademik. TI dituntut harus selaras dengan kegiatan bisnis [1]. Selain itu perguruan tinggi sangat membutuhkan informasi mengenai data alumni, kegiatan yang dilakukan oleh mahasiswa dan prestasi mahasiswa.

Pada saat ini pengelolaan pendataan alumni yang sering disebut Tracer Study pada STIA Satya Negara masih menggunakan sistem manual seperti memberikan form kertas yang berisi kuisoner pada saat satu minggu setelah wisuda, lalu pihak STIA Satya Negara mengumpulkan semua kertas yang telah dibagikan kepada alumni tersebut untuk di buatkan laporan pendataan alumni. Jika pihak kampus memperbaharui data alumni maka pihak kampus harus membongkar kertas-kertas form yang telah dibagikan kepada alumni sehingga memerlukan waktu yang cukup lama dan mengakibatkan kekeliruan pihak kampus. Para alumni juga mendapatkan informasi lowongan pekerjaan yang kurang efektif karena alumni diharuskan datang ke kampusuntuk mengetahui lowongan pekerjaan, karena pihak kampus hanya membagikan jika ada lowongan pekerjaan di mading. Kegiatan UKM pada STIA Satya Negara juga kurang berkembang sehingga mahasiswa yang ikut serta dalam kegiatan UKM tersebut sangat sedikit karena pihak kampus kurang meng-update kegiatan UKM yang ada pada kampus. Mahasiswa yang pernah membawa nama baik kampus STIA Satya Negara kurang diapresiasikan, karena apabila mahasiswa yang telah membawa nama baik tersebut tidak dikelola dengan baik maka data tersebut hanya menjadi tumpukan data yang tidak berguna. Prestasi mahasiswa bisa dijadikan strategis bagi kampus STIA Satya Negara tersebut.

Berdasarkan uraian tersebut diatas penulis tertarik untuk membuat tugas akhir dengan judul "Sistem Informasi Pengelolaan Data Kemahasiswaan berbasis Website pada STIA Satya Negara".

\section{METODE PENELITIAN}

Metode yang dipakai sebagai pengembangan aplikasi ini ialah metode iterasi. Metode iterasi yaitu metodologi campuran dari proses pada suatu metode yang setiap prosesnya atau fasenya dapat dilakukan secara berulang-ulang hingga menghasilkan yang diinginkan [2]. Metode iterasi memiliki 5 fase pengembangan sistem sebagai berikut :

\section{Fase Perencanaan}

Tahap fase perencanaan ini akan melakukan perencanaan terhadap pembuatan aplikasi yang akan dibuat permulaan sistem untuk mengidentifikasi permasalahan, menentukan ruang lingkup, serta melakukan wawancara dan observasi, serta merancang solusi untuk menyelesaikan permasalahan tersebut.

\section{Fase Analisis}

Tahap ini menganalisis mengenai pemahaman yang lebih menyeluruh terhadap permasalahan dan kebutuhan perangkat keras, perangkat lunak, serta kebutuhan umum untuk sistem yang dirancang, pada tahap ini, informasi-informasi melalui 
wawancara, observasi, dan studi pustaka yang dilakukan sebelumnya akan dianalisis, kemudian hasil dari analisis digunakan untuk tahap selanjutnya.

3. Fase Perancangan

Tahap ini yaitu melakukan perancangan desain baik tampilan luar aplikasi, dan coding. Tahap ini membantu untuk menjelaskan yang dibutuhkan perangkat keras dan menjelaskan arsitektur sistem secara keseluruhan.

4. Fase Implementasi

Tahap ini mengimplementasikan sistem, dimana aplikasi yang telah jadi akan diuji secara tersendiri untuk memastikan bahwa aplikasi dapat berjalan dengan benar dan memenuhi persyaratan yang ditetapkan.

5. Fase Pemeliharaan

Tahap ini merupakan tahap akhir dalam metode iterasi. Sistem yang telah dibuat akan dijalankan serta dilakukan pemeliharaan. Pemeliharaan yang dimaksud dapat berupa perbaikan pada kesalahan yang tidak dapat ditemukan pada tahapan sebelumnya, serta perbaikan implementasi unit system dan meningkatkan performa sistem.

\section{HASIL DAN PEMBAHASAN}

\subsection{Analisis Permasalahan}

Untuk melakukan analisis terhadap permasalahan yang terjadi maka penulis menggunakan kerangka PIECES yang berguna untuk mempermudah dalam mengklasifikasikan masalah tersebut. Pieces adalah model yang dapat digunakan untuk melakukan analisis permasalahan, dimana permasalahan diuraikan dalam 6 faktor yaitu, performance, information, economy, control, efficiency, service [3]. Analisis permasalahan dengan model PIECES dapat dilihat pada tabel 1.

Tabel 1 Klasifikasi Masalah Dalam Kerangka PIECES

\begin{tabular}{|l|l|}
\hline PIECES & \multicolumn{1}{|c|}{ Permasalahan } \\
\hline Performance & $\begin{array}{l}\text { Kinerja kampus dalam menyampaikan form } \\
\text { kuisioner hanya disampaikan dan dibagikan satu } \\
\text { persatu dan harus secara langsung. }\end{array}$ \\
\hline Information & $\begin{array}{l}\text { Pihak kampus membutuhkan waktu untuk } \\
\text { mendapatkan data yang akurat mengenai data } \\
\text { alumni, karena data tersebut harus diitung } \\
\text { terlebih dahulu untuk mengetahui seberapa } \\
\text { banyak alumni yang bekerja,tidak bekerja dan } \\
\text { membuka usaha sendiri. }\end{array}$ \\
\hline
\end{tabular}




\begin{tabular}{|l|l|}
\hline Economic & $\begin{array}{l}\text { Pengarsipan data-data Mahasiswa dan Alumni } \\
\text { masih menggunakan cara konvensional. Pihak } \\
\text { kampus memerlukan anggaran khusus untuk } \\
\text { membeli alat tulis kantor dan lemari untuk } \\
\text { penyimpanan data. }\end{array}$ \\
\hline Control & $\begin{array}{l}\text { Penyimpanan data saat ini masih bersifat } \\
\text { dokumen berupa kertas, sehingga mudah untuk } \\
\text { dimanipulasi dan diubah oleh pihak yang tidak } \\
\text { bertanggung jawab. }\end{array}$ \\
\hline Sficiency & $\begin{array}{l}\text { Perhitungan data saat ini masih dihitung secara } \\
\text { manual sehingga terjadi kesalahan perhitungan } \\
\text { data dan memakan waktu beberapa minggu. }\end{array}$ \\
\hline $\begin{array}{l}\text { Mahasiswa dan alumni kesulitan untuk } \\
\text { mendapatkan informasi lowongan pekerjaan } \\
\text { yang benar. }\end{array}$ \\
\hline
\end{tabular}

\subsection{Analisis Kebutuhan}

Berikut ini adalah gambaran diagram use case yang telah dirancang berdasarkan analisis kebutuhan fungsional yang telah dilakukan yang telah dilakukan dapat dilihat pada gambar 1. Use case adalah model yang dapat dimanfaatkan untuk melakukan analisis kebutuhan pengguna[4]. 


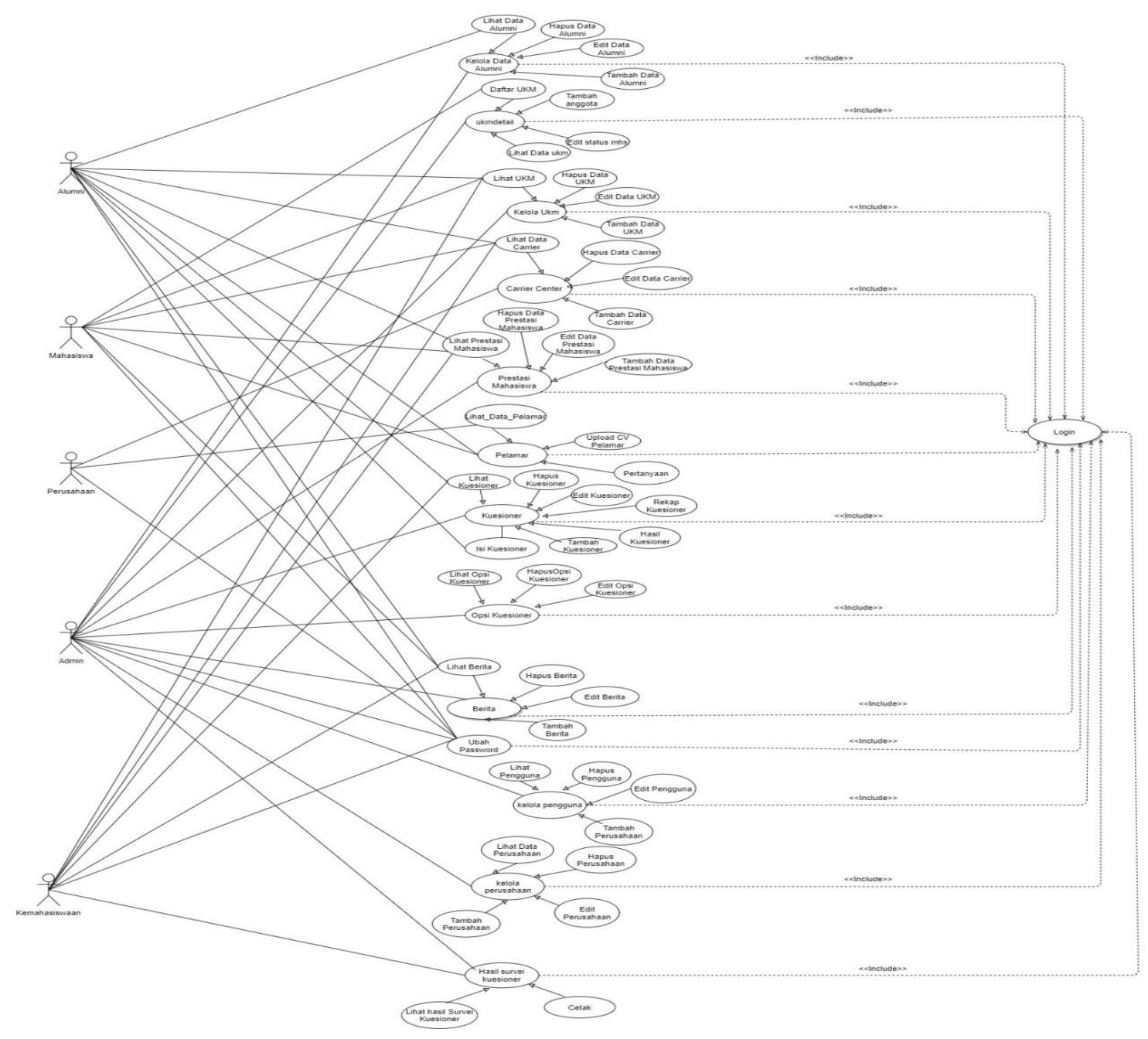

Gambar 1 :Use Case Diagram

\subsection{Diagram Konteks}

Diagram Konteks merupakan sebuah diagram yang mengilustrasikan ruang lingkup dari sistem yang diusulkan. Diagram konteks menunjukan antarmuka utama sistem dengan lingkungannya [5]. Diagram konteks pada sistem informasi pengelolaan data kemahasiswaan pada STIA Satya Negara diilustrasikan pada gambar 2 


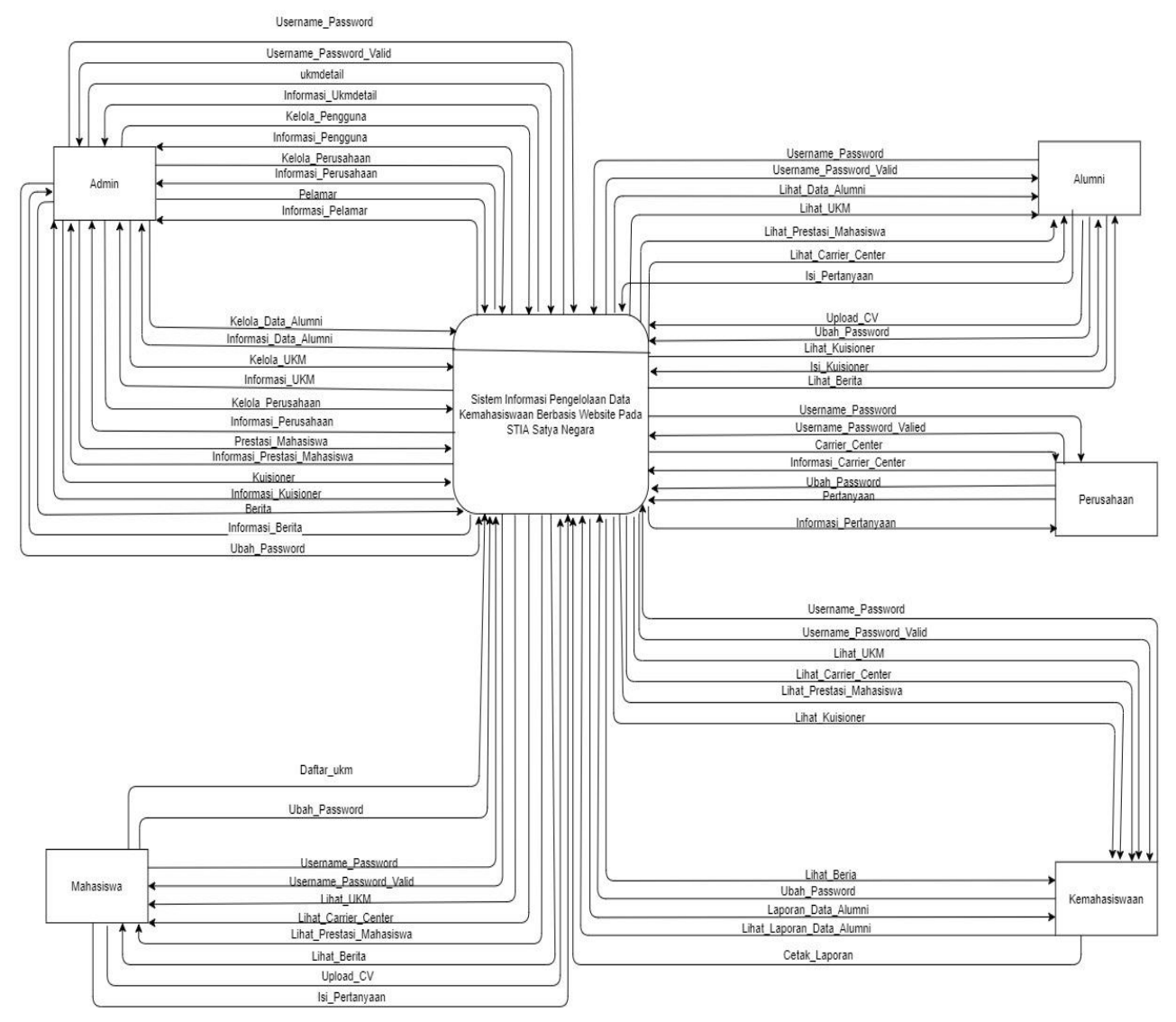

Gambar 2 : Diagram Konteks

\subsection{Diagram Dekomposisi}

Diagram Dekomposisi merupakan diagram yang mengilustrasikan sistem secara mendetail menjadi subsistem serta rincian dari masing-masing subsistem tersebut agar dapat lebih mudah dimengerti dan di analisis[6]. Diagram dekomposisi diilustrasikan pada gambar 3 


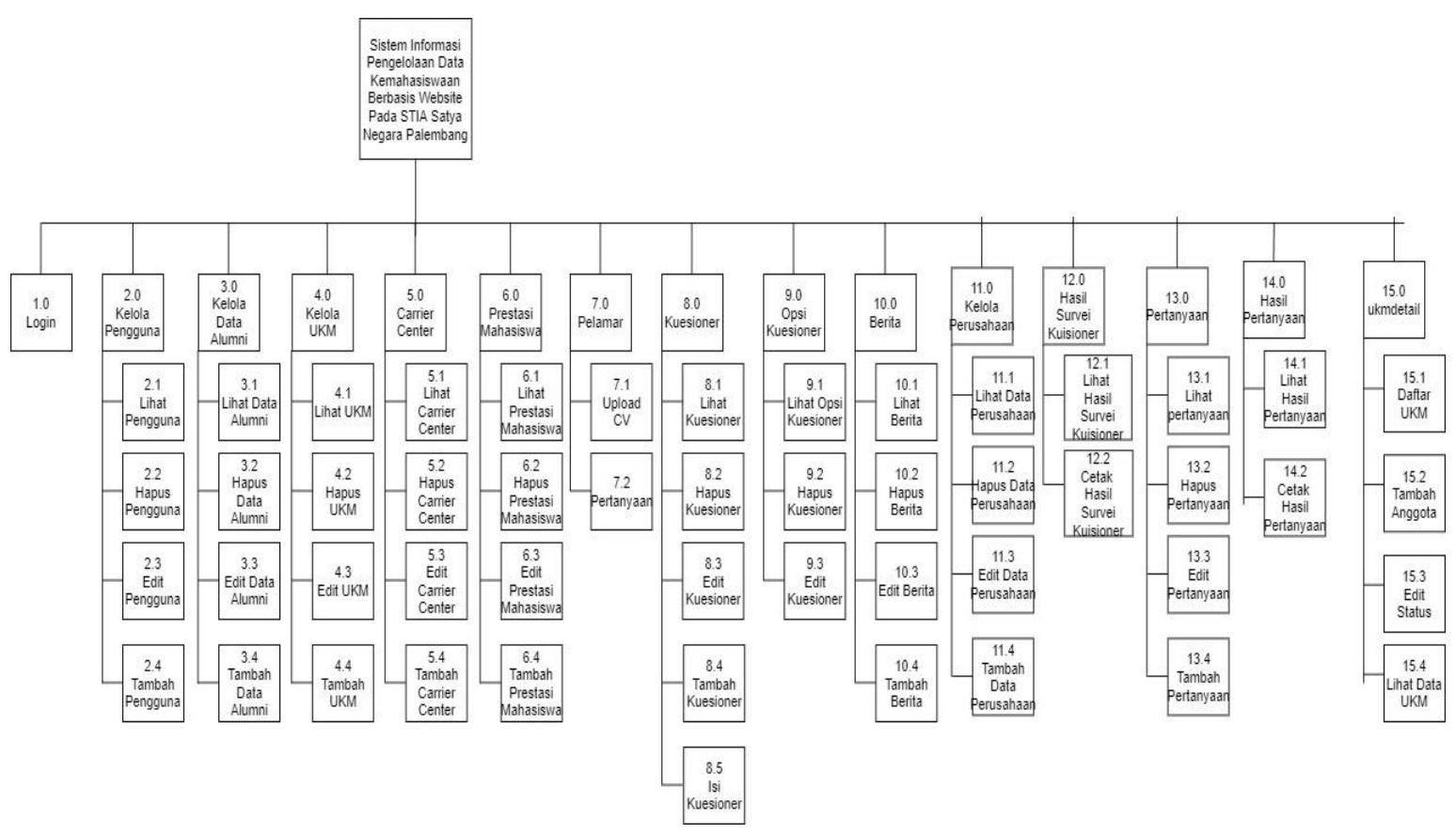

Gambar 3 : Diagram Dekomposisi

\subsection{Data Flow Diagram}

Data Flow Diagram yang diusulkan pada rancangan sistem dapat diilustrasikan pada gambar 4 


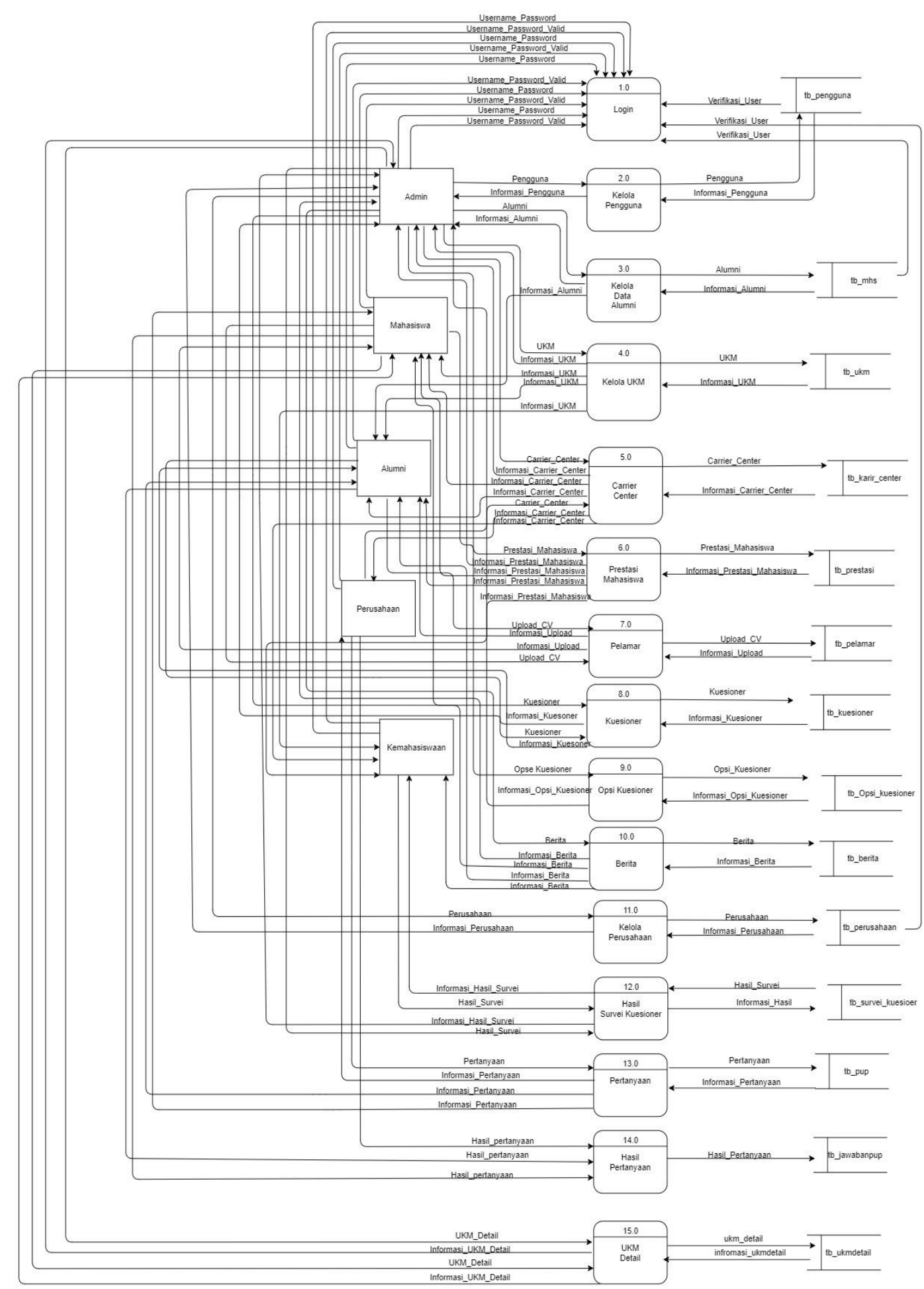

3.6 Tampilan Antar Muka

Gambar 4 : Data Flow Diagram

Berikut tampilan antarmuka sistem informasi pengelolaan data kemahasiswaan berbasis Website pada STIA Satya Negara Palembang. 


\subsubsection{Halaman Login}

Tampilan halaman login berfungsi sebagai proses autentikasi pengguna, dimana pengguna memasukkan username dan password dengan benar. Adapun bentuk tampilan Login Mahasiswa, Alumni, Admin, Perusahaan dan bagian Kemahasiswaan. Adapun bentuk tampilan Login dapat dilihat pada gambar 5.

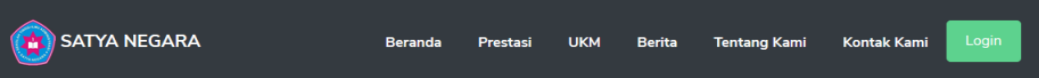

LOGIN SISTEM

NIM/ USERNAME PENGGUNA.

PASSWORD

LOGIN BATAL

Gambar 5 : Halaman Login

\subsubsection{Halaman Beranda}

Tampilan dibawah ini merupakan tampilan beranda pada sistem informasi pengelolaan data Kemahasiswaan dengan fitur Prestasi, UKM, Berita, Tentang Kami dan Kontak Kami. Adapun tampilan beranda dapat dilihat pada gambar 6

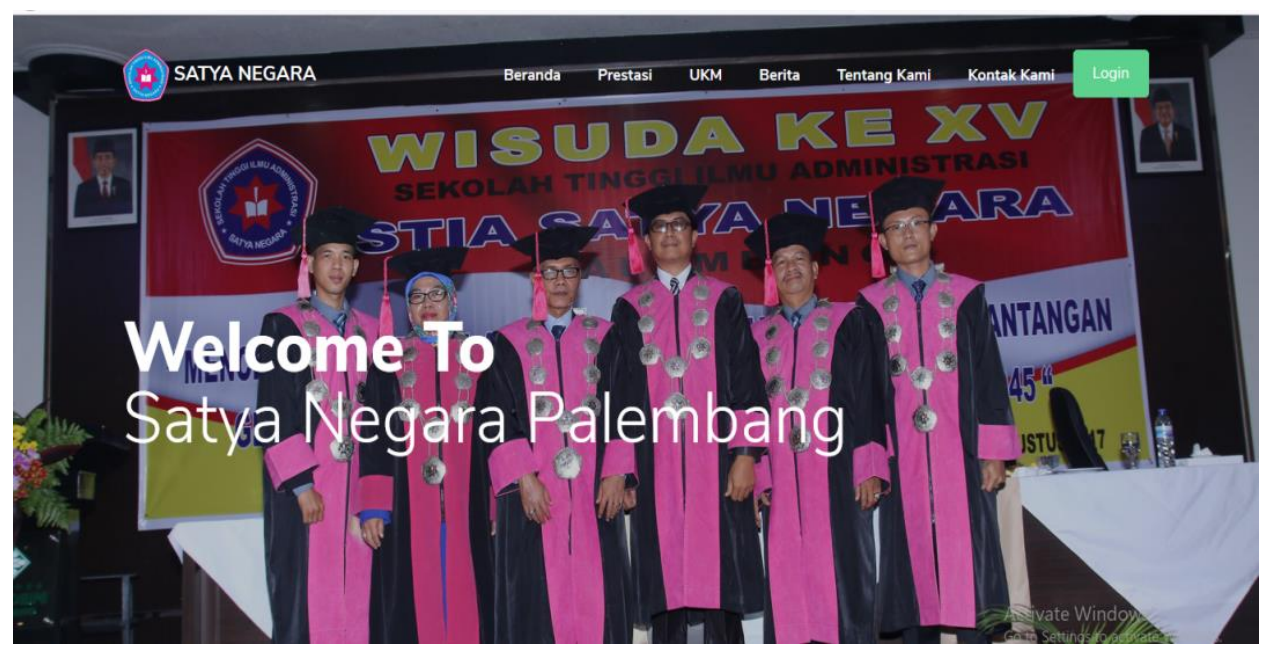

\section{Gambar 6 : Tampilan Halaman Beranda}

\subsubsection{Tampilan Form Berita}

Pada form ini berisi berita-berita atau isu-isu yang sedang hangat diperbincangkan atau informasi penting lainnya yang layak diunggah 
pada sistem ini. Adapun tampilan form Berita dapat dilihat pada gambar 7.

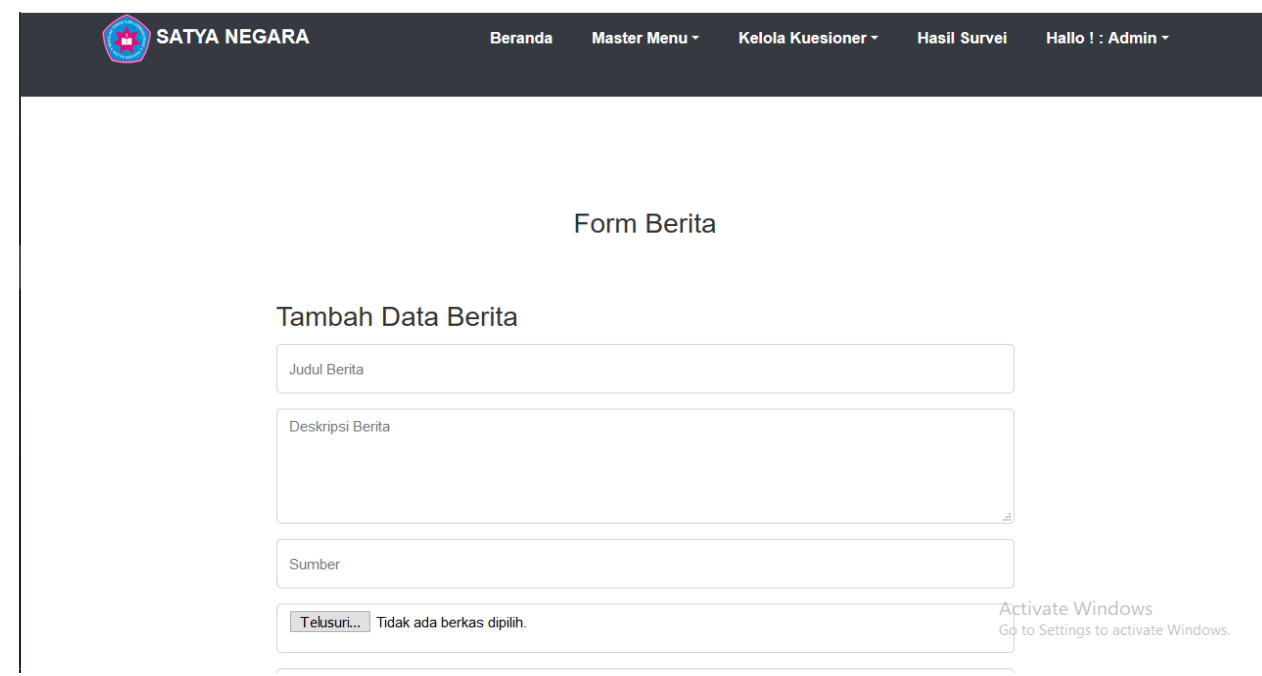

Gambar 7 : Tampilan Form Berita

\subsubsection{Tampilan Form Prestasi}

Tampilan form prestasi ini berfungsi untuk menambahkan datadata prestasi dari mahasiswa, dosen maupun dari kampus sendiri seperti telah meraih sebuah penghargaan. Adapun tampilan form prestasi dapat dilihat pada gambar 8

\section{- Satya negara \\ Beranda Master Menu - Kelola Kuesioner - Hasil Survei Hallo ! : Admin -}

Form Prestasi

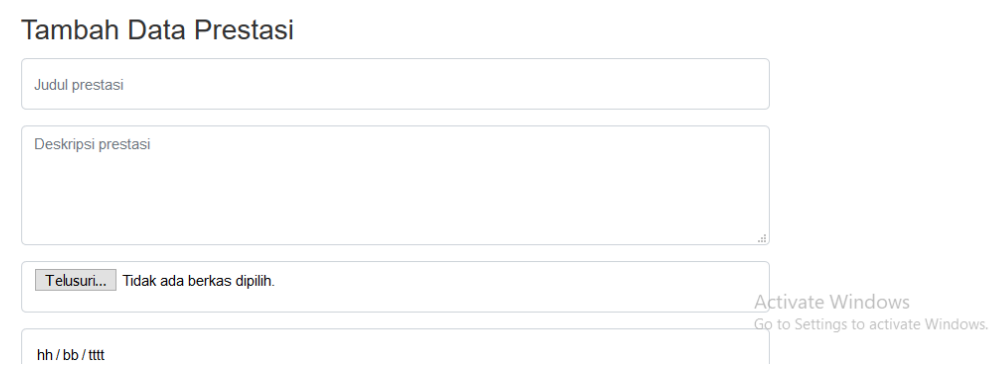

Gambar 8 : Tampilan Form Prestasi

\subsubsection{Tampilan Form UKM}

Tampilan form UKM berfungsi untuk menambahkan informasiinformasi atau data-data terkait UKM. Adapun tampilan form UKM dapat dilihat pada gambar 9 . 


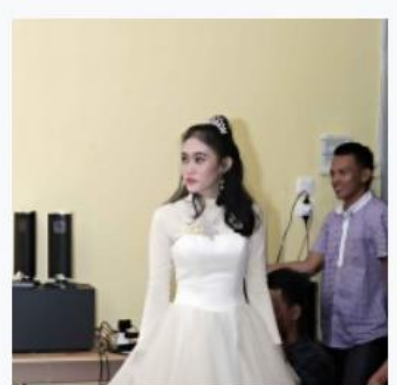

TGL POST : 2019-07-16

Modeling

Untuk para Mahasiswa yang

mempunyai kompetensi di dunia

Model tetapi tidak memiliki

kemampuan ataupu

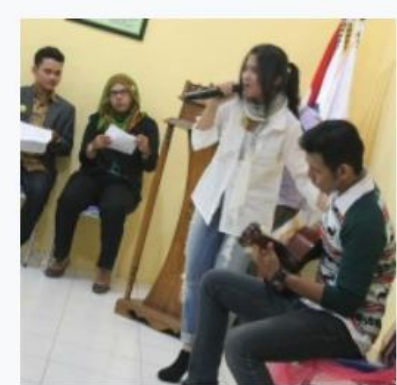

TGL POST : 2019-11-06

Paduan Suara

Paduan Suara merupakan unit kegiatan mahasiswa di tingkat universitas yang berfungsi sebagai wadah s

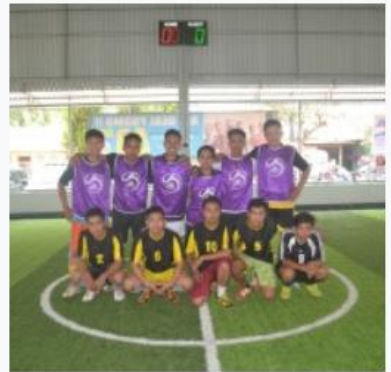

TGL. POST : 2019-11-03

futsal

UKM Futsal adalah jenis UKM yang bergerak di bilang olahraga terutama bola (futsal). UKM ini berdiri

Gambar 9 : Tampilan Form UKM

\subsubsection{Tampilan Carrier Center}

Tampilan dibawah ini merupakan tampilan carrier center perusahaan untuk mahasiswa maupun alumni yang sedang mencari lowongan pekerjaan. Adapun tampilan dari carrier center dapat diliht pada gambar 10

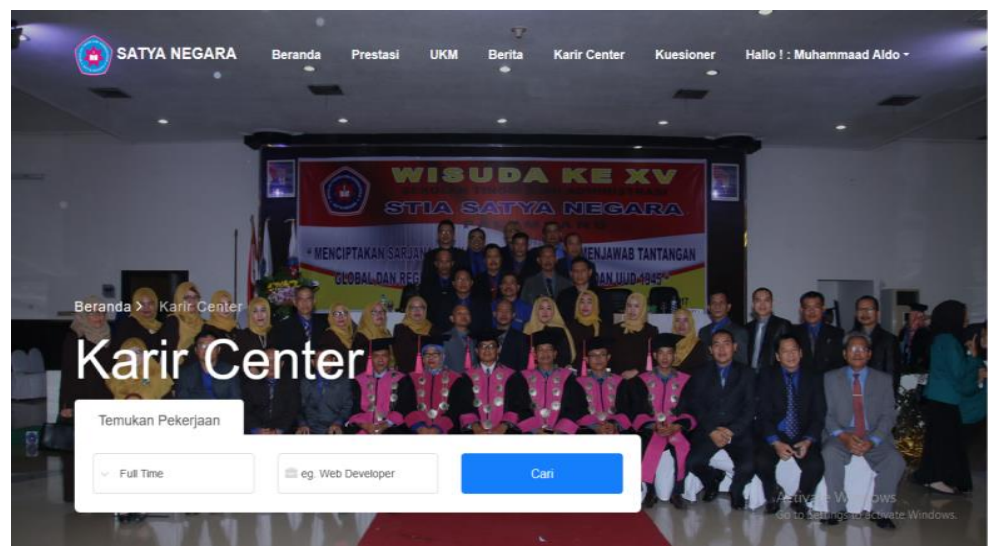

Gambar 10 : Tampilan Carrier Center 


\section{KESIMPULAN DAN SARAN}

\subsection{Kesimpulan}

Berdasarkan hasil penulisan yang sudah dijabarkan, maka penulis dapat menarik kesimpulanya itu dengan adanya aplikasi ini dapat membantu pihak STIA Satya Negara dalam mempromosikan atau meng-Update UKM, membantu mendapatkan informasi mengenai karir Alumni, mempermudah Mahasiswa dan Alumni untuk mendapatkan informasi lowongan pekerjaan yang cepat dan tepat, memberikan kemudahkan kepada STIA Satya Negara dalam pembuatan laporan data Alumni, ini pihak Kampus mudah untuk mendapatkan feedback dari Alumni dan Dengan adanya aplikasi ini pihak STIA Satya Negara dapat mencari Mahasiswa yang berprestasi.

\subsection{Saran}

Adapun saran yang diberikan adalah sebagai berikut:

1. Aplikasi yang dibuat sebaiknya segera digunakan sebagai mana mestinya untuk meningkatkan proses bisnis pada STIA Satya Negara.

2. Aplikasi sebaiknya segera dipakai agar dapat mempermudah STIA Satya Negara dalam pengelolaan seluruh informasi UKM, informasi carrier center, informasi data alumni, informasi prestasi dan pembuatan laporan data alumni.

\section{DAFTAR PUSTAKA}

[1] D. Pratama, "Pengukuran Keselarasan Strategi Teknologi Informasi Dan Strategi Bisnis Dengan Model Luftman (Studi Kasus : AMIK XYZ)," Semin. Nas. Inform., 2014.

[2] Rosa dan Shalahuddin, Rekayasa Perangkat Lunak (Terstrukur dan Berorientasi Objek). 2016.

[3] S. S. Husna, M. Fadli, and D. Hajar, "Rancang Bangun Sistem Pemesanan Tiket Bus Berbasis Mobile Dengan Metode PIECES (Studi Kasus: PO. Handoyo Dumai)," J. RESTI (Rekayasa Sist. dan Teknol. Informasi), 2018, doi: 10.29207/resti.v2i3.507.

[4] A. Gemino and D. Parker, "Use case diagrams in support of use case modeling: Deriving understanding from the picture," J. Database Manag., 2009, doi: 10.4018/jdm.2009010101.

[5] H. Al Fatta, Analisis dan Perancangan Sistem Informasi untuk Keunggulan Bersaing Perusahaan dan Organisasi Modern. 2007.

[6] F. Al Hanif, "Analisis \& Perancangan Sistem Informasi. Yogyakarta: Andi, 2007.," J. Teknol. Inf. Din., 2011. 